\title{
A Cross-Sectional Survey on Occupational Blood and Body Fluid Exposure Risk in a Tertiary Hospital in East Malaysia
}

This article was published in the following Dove Press journal: Risk Management and Healthcare Policy

\author{
Che Wan Ilmiyah C W \\ Ahmad (iD) ' \\ Khamisah Awang Lukman (iD) 2,3 \\ Raja Muhammad Raja Omar (D) \\ Mohammad Saffree Jeffree (D) ${ }^{3}$ \\ 'Hospital Queen Elizabeth, Kota \\ Kinabalu, Sabah, Malaysia; ${ }^{2}$ Center for \\ Occupational Safety and Health, \\ Universiti Malaysia Sabah, Kota Kinabalu, \\ Sabah, Malaysia; ${ }^{3}$ Community and Family \\ Medicine Department, Faculty of \\ Medicine and Health Sciences, Universiti \\ Malaysia Sabah, Kota Kinabalu, Sabah, \\ Malaysia
}

Background and Aim: Healthcare workers (HCWs) routinely experience occupational blood and body fluid exposure (OBBE), including percutaneous injury and splash exposure to non-intact skin. The objective of this study was to determine the prevalence of OBBE and identify associated risk factors.

Methods: A cross-sectional study was performed on $334 \mathrm{HCWs}$ at 9 workstations. Data were collected with a self-administered questionnaire that consisted of four parts: sociodemographic variables, work-related information, knowledge about needle stick and sharps injury and splash exposure, and information regarding previous OBBE incidents. The data were analyzed by SPSS version 22.0 software.

Findings: The prevalence of OBBE was 25.1\% (95\% confidence interval: 20.6-30.2), mostly due to percutaneous injuries, which were not reported to authorities. The highest proportions were among nurses and those working in the medical ward. Needle recapping practices were associated with almost a four-times higher risk of OBBE compared to norecapping practices. HCWs who did not have any infection prevention training had a threetimes higher risk of OBBE.

Conclusion: Factors associated with $\mathrm{OBBE}$ are unsafe work practices, inadequate infection prevention training, and lack of knowledge regarding blood-borne infection. There is a need for more training and increased awareness about the risks of OBBE to reduce unsafe practices.

Keywords: occupational blood and body fluid exposure, hospital

\section{Introduction}

Healthcare workers (HCWs) are involved in invasive procedures and regularly deal with patients' body fluids. This puts them at risk of occupational blood and body fluid exposure (OBBE) in their daily work routine. Exposure can occur via percutaneous injury (e.g., needle stick injury [NSI] or sharps injury) and splashes of blood to the eyes, mouth, nose, or non-intact skin. The main concern is the transmission of blood borne infections such as human immunodeficiency virus (HIV), hepatitis B virus (HBV), and hepatitis C virus (HCV). Other pathogens such as bacteria, parasites, and yeast can also be transmitted. ${ }^{1}$ An estimated 3 million of 35 million HCWs had percutaneous exposures to blood borne pathogen, and of these $37.6 \%$ contracted HBV, 39\% HCV, and 4.4\% HIV/acquired immunodeficiency syndrome (AIDS). ${ }^{2}$ Transmission risk increases with the dose of the infectious inoculum, either the volume of blood inoculated (deep needlestick,
Correspondence: Khamisah Awang Lukman Email khamisah@ums.edu.my 
large-bore needle, large surface of nonintact skin exposed) or the number of infective agents (high viral load, bacteremia, or parasitemia) contained in it. ${ }^{1}$ Among HCWs, nurses have the highest rate of NSI. ${ }^{3-5}$ Many factors contribute to the incidence of OBBE among HCWs, such as poor adherence to standard precautions, needle recapping after procedures, and improper handling of contaminated sharp devices or cleaning instruments. ${ }^{3,6,7}$ The reported range of prevalence in NSI or sharps injuries is $20.9 \%$ to $31.6 \%{ }^{6,8,9}$ One local study reported 378 cases of NSI over 10 years from 1999 until 2008; this was equivalent to 37.8 cases per year, with most instances occurring in hospital settings. ${ }^{10}$ The reported cases mostly occurred during intravenous procedures and disposal. Even though awareness interventions are implemented, there remains a need to identify factors associated with OBBE. In 2005, the Malaysian Ministry of Health reported an incidence rate of $4.7 \mathrm{NSI}$ per $1000 \mathrm{HCWs}^{11}$ OBBE reporting is done through the national Sharp Injury and Surveillance (SIS) program. Any injury or exposure should be reported to the location supervisor, and they will immediately refer the affected person to the designated doctor from the medical department for assessment and post-exposure prophylaxis if necessary. ${ }^{11}$ The location supervisor needs to notify hospital Occupational Health Unit (OHU) of the incident, and the $\mathrm{OHU}$ is responsible for recording the incidence in the SIS and following up with the affected individual at 6 weeks, 3 months, and 6 months. HBV immunization is already administered to all HCWs. Identifying OBBE risk factors will help hospital management develop targeted prevention and action plans to reduce OBBE among its HCWs. This study aimed to determine the prevalence and associated factors of OBBE among HCWs in a tertiary government hospital.

\section{Methods and Materials}

This cross-sectional study was conducted in a tertiary hospital in Sabah, Malaysia. It has 775 beds with a $73.3 \%$ average annual occupancy rate from 2016 to 2018. In 2018, it employed a varied range of professionals including doctors $(n=1118)$, nurses $(n=1573)$, hospital assistants $(n=356)$, lab technicians $(n=152)$, and maintenance technicians $(n=35)$. There was increasing trend of OBBE reported, with $78 \%$ more exposures in 2018 compared to 2016 ( 80 vs. 45, respectively). The calculated sample size of 346 was based on the $23.5 \%$ prevalence of $\mathrm{NS}^{6}{ }^{6}$ considering a $20 \%$ non-response rate, $95 \%$ confidence intervals (CIs), and a precision of 0.05 .
All workstations in the hospital were identified, and a subset were chosen using stratified random sampling. The nine workstations identified were the emergency department, operating room, medical ward, surgical ward, maintenance station, medical lab, intensive care unit, blood bank, and dental clinic. These places are at a higher risk of OBBE. Sample populations included all staff who worked in the nine workstations including nurses $(n=285)$, doctors $(n=67)$, laboratory technicians $(n=20)$, and maintenance technicians $(n=35)$. A selfadministered paper questionnaire was distributed to all staff who worked in the nine workstations and then collected after 3 days. All results were kept anonymous. The questionnaire used in this study consisted of closeended questions adapted from a previous study. ${ }^{12}$ It included questions on sociodemographic variables, workrelated information, knowledge about NSI and sharps injury and splash exposure, and information regarding previous OBBE incidents. The purpose of the study was explained to each participant, and written consent was obtained prior to study commencement. It was piloted to 20 clinical staff members in workstations that were not included in the study. All completed questionnaires were entered in IBM SPSS version 22.0. Sociodemographic data are presented as descriptive statistics. Chi-square tests were used to test relationships between categorical variables. All analyses with statistically significant relationships were further analyzed by simple logistic regression to determine the magnitudes of the associations. OBBE was defined as an exposure over the past year that might place healthcare personnel at risk of $\mathrm{HBV}$, $\mathrm{HCV}$, or HIV infection through percutaneous injury, contact of mucous membranes or non-intact skin with blood, tissue, or other body fluids that are potentially infectious. Ethics approval for Queen Elizabeth Hospital was obtained from the ethics committee, and the study was conducted in compliance with the ethical principles outlined in the Declaration of Helsinki and Good Clinical Practice Guideline. This study was approved by the Medical Research and Ethics Committee, Ministry of Health.

\section{Results}

Of 400 questionnaires, 352 were returned, corresponding to an $88 \%$ response rate. Eighteen questionnaires were not completed and were thus excluded from the analysis. A total of 334 questionnaires were used for the final analysis. Most respondents were female (mean age of 
31 years old), employed as nurses, had a diploma education level, worked in the medical ward, had a service duration of $\sim 5$ years, and worked in shifts (Table 1 ). In terms of work practices, most respondents did not practice needle recapping, regularly wore personal protective equipment (PPE), had completed infection prevention

Table I Respondent Profiles and Univariate Analysis of OBBE Factors Among HCWs

\begin{tabular}{|c|c|c|c|c|c|}
\hline Factor & $\begin{array}{l}\text { Respondent Frequency (\%) } \\
\qquad(\mathrm{N}=334)\end{array}$ & $\begin{array}{l}\text { OBBE } \\
(n=84)\end{array}$ & $\begin{array}{l}\text { Non OBBE } \\
(n=250)\end{array}$ & $\chi^{2}$ or $t$-Test & $p$ \\
\hline Age & & 30.52 & 31.23 & 0.97 & 0.33 \\
\hline \multicolumn{6}{|l|}{ Sex } \\
\hline Male & $58(17.3 \%)$ & $20(34.5 \%)$ & 38 (65.5\%) & 3.25 & 0.07 \\
\hline Female & $276(82.6 \%)$ & $64(23.2 \%)$ & $212(76.8 \%)$ & & \\
\hline \multicolumn{6}{|l|}{ Education level } \\
\hline$<$ Secondary school & $19(5.6 \%)$ & $5(26.3 \%)$ & 14 (73.7\%) & & 1.00 \\
\hline$\geq$ Diploma & 315 (94.4\%) & 79 (25. I\%) & $236(74.9 \%)$ & & \\
\hline \multicolumn{6}{|l|}{ Profession } \\
\hline Nurse & 250 (74.9\%) & 49 (58.3\%) & 201 (80.4\%) & & \\
\hline Doctor & 47 (I4.1\%) & $22(26.2 \%)$ & $25(10.0 \%)$ & & \\
\hline Lab technician & $23(6.9 \%)$ & 7 (8.3\%) & $16(6.4 \%)$ & & \\
\hline Maintenance technician & 14 (4.I\%) & $6(7.1 \%)$ & $8(3.2 \%)$ & & \\
\hline \multicolumn{6}{|l|}{ Workstation: } \\
\hline Emergency department & 39 (II.7\%) & $16(19.0 \%)$ & $23(9.2 \%)$ & & \\
\hline Operation room & I5 (4.5\%) & $5(6 \%)$ & $10(4.0 \%)$ & & \\
\hline Medical ward & $139(41.6 \%)$ & $24(28.6 \%)$ & 115 (46.0\%) & & \\
\hline Surgical ward & 75 (22.4\%) & $14(16.7 \%)$ & 61 (24.4\%) & & \\
\hline Maintenance station & $13(3.9 \%)$ & $5(6.0 \%)$ & $8(3.2 \%)$ & & \\
\hline Medical lab & 19 (5.7\%) & 7 (8.3\%) & $12(4.8 \%)$ & & \\
\hline Palliative care unit & $13(3.9 \%)$ & $8(9.5 \%)$ & $5(2.0 \%)$ & & \\
\hline Blood bank & 14 (4.2\%) & $2(2.4 \%)$ & $12(4.8 \%)$ & & \\
\hline Dental clinic & 7 (2.1\%) & $3(3.6 \%)$ & $4(1.6 \%)$ & & \\
\hline Years of service & & 5.0 & 5.8 & 1.48 & 0.57 \\
\hline \multicolumn{6}{|l|}{ Shift work } \\
\hline Yes & $246(73.7 \%)$ & $57(23.2 \%)$ & I89 (76.8\%) & 1.94 & 0.16 \\
\hline No & $88(26.3 \%)$ & $27(30.7 \%)$ & $61(69.3 \%)$ & & \\
\hline \multicolumn{6}{|l|}{ Needle recapping } \\
\hline Yes & 48 (14.4\%) & $24(50.0 \%)$ & $24(50.0 \%)$ & 18.39 & 0.00 \\
\hline No & $286(85.6 \%)$ & $60(21.0 \%)$ & $226(79.0 \%)$ & & \\
\hline \multicolumn{6}{|l|}{ Adherence to universal precautions } \\
\hline No & 79 (23.7\%) & $16(20.3 \%)$ & $63(79.7 \%)$ & 1.32 & 0.25 \\
\hline Yes & 255 (76.3\%) & $68(26.7 \%)$ & $187(73.3 \%)$ & & \\
\hline \multicolumn{6}{|l|}{$\begin{array}{l}\text { Personal protective equipment } \\
\text { usage }\end{array}$} \\
\hline Yes & $328(98.2 \%)$ & 81 (24.7\%) & $247(75.3 \%)$ & & 0.17 \\
\hline No & $6(1.8 \%)$ & $3(50.0 \%)$ & $3(50.0 \%)$ & & \\
\hline \multicolumn{6}{|l|}{ Infection prevention training } \\
\hline Yes & 287 (85.9\%) & $62(21.6 \%)$ & 225 (78.4\%) & 13.63 & 0.00 \\
\hline No & 47 (14.1\%) & $22(46.8 \%)$ & $25(53.2 \%)$ & & \\
\hline Knowledge of blood borne infection & & 18.54 & 18.25 & -1.47 & 0.19 \\
\hline
\end{tabular}

Abbreviations: HCW, healthcare worker; OBBE, occupational blood and body fluid exposure. 
training, and adhered to universal precautions. There were 84 respondents who had been exposed to blood and body fluids at work, and the prevalence of OBBE was $25.1 \%$ (95\% CI: 20.6-30.2). Overall, $87 \%$ of these incidents were due to percutaneous injury and the remaining were splash exposures. Almost half of the respondents did not report OBBE events. Most OBBE were among nurses and HCWs working in the medical ward. There was a significant statistical association between OBBE with needle recapping, training on infection prevention, and better knowledge of blood borne infection. Other factors such as gender, age, education level, years of service, shift work, adherence to universal precaution, and PPE use were not significantly associated with OBBE. In an additional analysis, respondents who practiced needle recapping were almost four times more likely to have OBBE compared to respondents who did not practice needle recapping (adjusted odds ratio [AOR] $=4.17$, 95\% CI: 2.09-8.33; Table 2). Notably, respondents who did not attend any infection prevention training had a three-fold higher risk of OBBE compared to those who attended the training $(\mathrm{AOR}=2.95,95 \% \mathrm{CI}$ : 1.50-5.79). Knowledge of blood borne infection was significantly associated with OBBE (AOR=1.22, 95\% CI: 1.00-1.49).

\section{Discussion}

This study showed that the prevalence of OBBE among HCWs in a tertiary hospital was $25.1 \%$. The rate was similar to those reported in other Malaysian hospitals. ${ }^{6,8}$ The majority of the cases $(85.7 \%)$ involved percutaneous injuries, with fewer cases of splash exposure (14.3\%). Percutaneous injuries were associated with ampoule and syringe needle usage. These occurred during waste handling and collection, sudden patient movement, while opening the needle cap, were accidental injuries caused by the carelessness of a colleague, and injuries due to improper needle disposal. Fortunately, these were superficial skin injuries, and the individuals were immunized against HBV. A Tunisian study also found that the primary mechanism of blood and body fluid exposure was accidental NSI among health staff and trainees. The authors concluded that a higher severity of blood exposure accidents was linked to the lack of safe behaviors to mitigate risk. $^{13}$ Existing control measures for OBBE prevention include monthly training, standard operating procedure implementation, and PPE use. Most incidents were not reported to an authority. This suggests a likely higher prevalence of OBBE than the reported data suggest. The reasons for this are as follows: the needle that injured these individuals was never used in a patient, individuals were busy with work, the sharp objects were used on patients who had no infectious disease of concern, and-possibly the reason of greatest concern - individuals did not know how to report the incidence. Another group revealed that the major reason for individuals not reporting their injuries to an authority was that the subjects felt it to be unnecessary. Failure to see the importance of reporting and a lack of mandatory reporting are possible reasons for not disclosing OBBE, and the importance of reporting needs to be emphasized. ${ }^{14}$ In this study, half of the exposures affected nurses. This is comparable to other studies where nurses frequently experienced OBBE. ${ }^{4,5,15}$ Nurses have frequent contact with patients and perform most of the procedures such as blood collection, intravenous line insertion, and medication administration. In France, nurses and nursing students accounted for 4587 (60\%) exposures, followed by nurses' aides and clinicians; most were related to NSI. ${ }^{16}$ Overall, occupational exposure among HCWs in tertiary hospitals occur most often in the medical ward, followed by the emergency department, surgical ward, and other places. A study in Sabah reported similar results, with a higher occurrence in the medical and surgical wards. ${ }^{10}$ Another study reported that most occupational accidents due to NSIs occurred in the emergency unit. ${ }^{17}$ Medical and surgical wards perform numerous risky procedures, such as

Table 2 Multivariate Analysis of OBBE Factors Among HCWs

\begin{tabular}{|l|c|c|c|}
\hline Factor & Adjusted Odds Ratio & (95\% Confidence Interval) & $\mathbf{P}$ \\
\hline Needle recapping & 4.17 & $(2.09-8.33)$ & $<0.05$ \\
Did not attend training & 2.95 & $(1.50-5.79)$ & $<0.05$ \\
Age & 0.97 & $(0.87-1.08)$ & $>0.05$ \\
Total years in service & 0.99 & $(0.89-1.10)$ & $>0.05$ \\
Knowledge scoring & 1.22 & $(1.00-1.49)$ & $<0.05$ \\
Standard precaution adherence & 0.54 & $(0.28-1.04)$ & $>0.05$ \\
\hline
\end{tabular}

Abbreviations: HCW, healthcare worker; OBBE, occupational blood and body fluid exposure. 
intravenous line insertion, central line insertion, and surgical procedures, which would explain the higher prevalence of OBBE was higher in these departments. Emergency and intensive care staff had the highest relative rates compared with maintenance staff, and nurses and laboratory staff were more exposed than physicians. Prompt prevention and training need to be efficiently devised and precisely focused. ${ }^{18}$ For example, needle recapping practices are associated with an almost four-time higher risk of sharps injury compared to not recapping. These were likely related to inadequate knowledge and inability to identify the danger of the practice. ${ }^{1,6,12}$ An assessment of workplace layout identified that sharps disposal container distance from the procedure setting might contribute to needle recapping. Proper planning before the procedure such as placing a reachable sharp bin for disposal will help prevent NSI. In a survey of licensed paramedics, most needle/lancet sticks involved non-safety devices. The authors suggested that blood exposure could be reduced through increased use of safety devices and PPE, improved engineering and design, increased compliance with universal precautions, and a need for techniques that avoid blood exposure while treating uncooperative or combative patients. ${ }^{19}$ However, there was no retractable needle used in the studied hospital. This issue should be considered to help minimize OBBE risk. Diminishing the frequency with which nurses recap needles, increasing the precautions they take, reducing use of temporary nursing personnel, and implementing organizational changes may lower the risk of nurses being injured. ${ }^{20}$ Staff training on infection prevention also plays an important role in mitigating OBEE risk. HCWs who did not have any infection prevention training had a three-fold higher risk of OBBE. Inadequate training was also cited as a risk factor in other studies. ${ }^{3,21}$ Continuous and more frequent training and education programs for staff are needed to increase awareness and improve practices in handling needles and sharps. Frequent hospital administration messages through phone or email to all staff could highlight the importance of safe sharps handling and disposal to further increase awareness. Training will improve HCW knowledge and awareness and help them to implement these tools into their practice with a new ability to identify the dangers of OBBE, including $\mathrm{HBV}, \mathrm{HCV}$, and HIV infection. HBV vaccination produces immunity against infection, ${ }^{22}$ so completing the vaccination series is important to develop protection against HBV. Lack of awareness and insufficient monitoring of HBV immunity among HCWs both contributed to lower HBV vaccination completion. A system and procedure to monitor $\mathrm{HBV}$ immunity status is important to ensure adequate infection protection. Therefore, a rigorous approach including more training sessions, continuous communication on the risk of OBBE, and the need to comply with standard precautions to the staff through various platforms should be implemented. In summary, busy hospitals, unsafe work practices, and a lack of resources contributed to the high prevalence of OBBE in this study. Increased resource allocation and ensuring sustainability will promote safe work practices among HCWs. In conclusion, the prevalence of OBBE among HCWs in a tertiary hospital was $25.1 \%$. The factors associated with OBBE were unsafe work practice, inadequate infection prevention training, and lack of knowledge regarding blood borne infection. There is a need for more training and increased awareness of the risks of OBBE to reduce unsafe practices.

\section{Limitations}

The study findings cannot be generalized to all HCWs, as the study was performed in one tertiary hospital that has more resources than smaller hospitals.

\section{Acknowledgments}

We would like to express our sincere gratitude to the Director of the Hospital and Sabah State Health Department for their support and cooperation. This study was not supported by a grant.

\section{Disclosure}

The authors report no conflicts of interest in this work.

\section{References}

1. Tarantola A, Abiteboul D, Rachline A. Infection risks following accidental exposure to blood or body fluids in health care workers: a review of pathogens transmitted in published cases. Am J Infect Control. 2006;34(6):367-375. doi:10.1016/j.ajic.2004.11.011

2. World Health Organization (WHO). The World Health Report 2002. Geneva: World Health Organization; 2002.

3. Motaarefi H, Mahmoudi H, Mohammadi E, Hasanpour-dehkordi A. Factors associated with needlestick injuries in health care occupations: a systematic review. J Clin Diagn Res. 2016;10(8):IE011-IE04. doi:10.7860/JCDR/2016/17973.8221

4. Afridi AAK, Kumar A, Sayani R. Needle stick injuries - risk and preventive factors: a study among health care workers in tertiary care hospitals in Pakistan. Glob J Health Sci. 2013;5(4):85-92. doi:10.5539/gjhs.v5n4p85

5. Türe Z, Ulu Kiliç A, Cevahir F, Altun D, Özhan E, Alp E. Predictive factors for percutaneous and mucocutaneous exposure among healthcare workers in a developing country. J Epidemiol Glob Health. 2016;6(3):141-146. doi:10.1016/j.jegh.2015.06.003

6. Rampal L, Zakaria R, Sook LW. Needle stick and sharps injuries and factors associated among health care workers in a Malaysian Hospital. Eur J Soc Sci. 2010;13(3):354-362. 
7. Markovic-Denic L, Maksimovic N, Marusic V, Vucicevic J, Ostric I, Djuric D. Occupational exposure to blood and body fluids among health-care workers. Med Princ Pract. 2015;24(1):36-41. doi: $10.1159 / 000368234$

8. Bhardwaj A, Sivapathasundaram N, Yusof M, Minghat A, Swe K, Sinha N. The prevalence of accidental needle stick injury and their reporting among healthcare workers in orthopaedic wards in general hospital Melaka, Malaysia. Malays Orthop J. 2014;8(2):6-13. doi:10.5704/MOJ.1407.009

9. Ng YW, Hassim IN. Needlestick injury among medical personnel in accident and emergency department of two teaching hospitals. Med $J$ Malaysia. 2007;62(1):9-12.

10. Lim JF, Safree J, Richard A, et al. An epidemiology of reported needlestick injuries among health care workers in sabah health government facilities from 1999 - 2008. J Adv Res Med. 2015;1 (1):21-30.

11. Guidelines on Occupational Exposures to HIV, HBV, and HCV and Recommendations for Post Exposure Prophylaxis (PEP). Putrajaya: Ministry of Health Malaysia; 2007.

12. Bekele T, Gebremariam A, Kaso M, Ahmed K. Attitude, reporting behaviour and management practice of occupational needle stick and sharps injuries among hospital healthcare workers in Bale Zone, Southeast Ethiopia: a Cross-Sectional Study. J Occup Med Toxicol. 2015;10(1):42. doi:10.1186/s12995-015-0085-2

13. Hajjaji Darouiche $M$, Chaabouni $T$, Jmal Hammami $K$, et al. Occupational blood exposure among health care personnel and hospital trainees. Int J Occup Environ Med. 2014;5(1):57-61.

14. Nelsing S, Nielsen TL, Nielsen JO. Occupational blood exposure among health care workers: i. frequency and reporting. Scand J Infect Dis. 1993;25:2, 193-198. doi:10.3109/00365549309008484
15. Memish ZA, Assiri AM, Eldalatony MM, Hathout HM, Alzoman H, Undaya M. Risk analysis of needle stick and sharp object injuries among health care workers in a Tertiary Care Hospital (Saudi Arabia). J Epidemiol Glob Health. 2013;3(3):123-129. doi:10.1016/ j.jegh.2013.03.004

16. Tarantola A, Golliot F, Astagneau P, et al. Occupational blood and body fluids exposures in health care workers: four-year surveillance from the Northern France network. Am J Infect Control. 2003;31 (6):357-363. doi:10.1016/S0196-6553(03)00040-3

17. Ashat M, Bhatia V, Puri S, Thakare M, Koushal V. Original article needle stick injury and HIV risk among health care. Indian J Med Sci. 2011;65(9):371-378. doi:10.4103/0019-5359.108947

18. Denis MA, Ecochard R, Bernadet A, et al. Risk of occupational blood exposure in a cohort of 24,000 hospital healthcare workers: position and environment analysis over three years. J Occup Environ Med. 2003;45(3):283-288. doi:10.1097/01.jom.0000052961.59271.9d

19. Leiss JK, Sousa S, Boal WL. Circumstances surrounding occupational blood exposure events in the National Study to prevent blood exposure in paramedics. Ind Health. 2009;47(2):139-144. doi:10.2486/indhealth.47.139

20. Aiken LH, Sloane DM, Klocinski JL. Hospital nurses‘ occupational exposure to blood: prospective, retrospective, and institutional reports. Am J Public Health. 1997;87(1):103-107. doi:10.2105/ AJPH.87.1.103

21. Kasatpibal N, Whitney JD, Katechanok S, et al. Prevalence and risk factors of needlestick injuries, sharps injuries, and blood and body fluid exposures among operating room nurses in Thailand. $\mathrm{Am}$ J Infect Control. 2016;44(1):85-90. doi:10.1016/j.ajic.2015.07.028

22. Said ZNA. Induced immunity against hepatitis B virus. World J Hepatol. 2015;7(12):1660-1670. doi:10.4254/wjh.v7.i12.1660
Risk Management and Healthcare Policy

\section{Publish your work in this journal}

Risk Management and Healthcare Policy is an international, peerreviewed, open access journal focusing on all aspects of public health, policy, and preventative measures to promote good health and improve morbidity and mortality in the population. The journal welcomes submitted papers covering original research, basic science, clinical \& epidemiological studies, reviews and evaluations,

\section{Dovepress}

guidelines, expert opinion and commentary, case reports and extended reports. The manuscript management system is completely online and includes a very quick and fair peer-review system, which is all easy to use. Visit http://www.dovepress.com/testimonials.php to read real quotes from published authors. 